This is an electronic reprint of the original article. This reprint may differ from the original in pagination and typographic detail.

\author{
Author(s): Brown, Zachary; Vasko, Petra; Erickson, Jeremy; Fettinger, James; Tuononen, Heikki; \\ Power, Philip
}

Title: $\quad$ Mechanistic Study of Stepwise Methylisocyanide Coupling and $\mathrm{C}-\mathrm{H}$ Activation Mediated by a Low-Valent Main Group Molecule

Year: $\quad 2013$

Version:

Please cite the original version:

Brown, Z., Vasko, P., Erickson, J., Fettinger, J., Tuononen, H., \& Power, P. (2013). Mechanistic Study of Stepwise Methylisocyanide Coupling and C-H Activation Mediated by a Low-Valent Main Group Molecule. Journal of the American Chemical Society, 135(16), 6257-6261. https://doi.org/10.1021/ja4003553

All material supplied via JYX is protected by copyright and other intellectual property rights, and duplication or sale of all or part of any of the repository collections is not permitted, except that material may be duplicated by you for your research use or educational purposes in electronic or print form. You must obtain permission for any other use. Electronic or print copies may not be offered, whether for sale or otherwise to anyone who is not an authorised user. 


\title{
Mechanistic Study of Stepwise Methylisocyanide Coupling and C-H Activation Mediated by a Low-Valent Main Group Molecule
}

Zachary D. Brown, ${ }^{\dagger}$ Petra Vasko, ${ }^{\neq}$Jeremy D. Erickson, ${ }^{\dagger}$ James C. Fettinger, ${ }^{\dagger}$ Heikki M. Tuononen,${ }^{\ddagger}$ and Philip P. Power ${ }^{\dagger} *$

${ }^{\dagger}$ Department of Chemistry, University of California, 1 Shields Avenue, Davis, CA 95616, and

${ }^{+}$Department of Chemistry, University of Jyväskylä, P.O. Box 35, FI-40014 Jyväskylä, Finland

\begin{abstract}
An experimental and DFT investigation of the mechanism of the coupling of methylisocyanide and C-H activation mediated by the germylene (germanediyl) $\mathrm{Ge}\left(\mathrm{Ar}^{\mathrm{Me} 6}\right)_{2}\left(\mathrm{Ar}^{\mathrm{Me} 6}=\right.$ $\left.\mathrm{C}_{6} \mathrm{H}_{2}-2,6\left(\mathrm{C}_{6} \mathrm{H}_{2}-2,4,6-\mathrm{Me}_{3}\right)_{2}\right)$ showed that it proceeded by initial MeNC adduct formation and sequential insertions of two MeNC molecules into a Ge-C bond. Insertion of a third MeNC leads to methylisocyanide methyl group C-H activation to afford an azagermacyclopentadienyl complex. The Xray crystal structures of the $1: 1\left(\mathrm{Ar}^{\mathrm{Me}}\right)_{2} \mathrm{GeCNMe}$ adduct, the first and final insertion products $\left(\mathrm{Ar}^{\mathrm{Me} 6}\right) \mathrm{GeC}(\mathrm{NMe}) \mathrm{Ar}^{\mathrm{Me} 6}$ and $\left(\mathrm{Ar}^{\mathrm{Me} 6}\right) \mathrm{GeC}(\mathrm{NHMe}) \mathrm{C}(\mathrm{NMe}) \mathrm{C}\left(\mathrm{Ar}^{\mathrm{Me} 6}\right) \mathrm{NMe}$ were obtained. The DFT calculations on the reaction pathway represent the first detailed mechanistic study of isocyanide oligomerization by a p-block element species.
\end{abstract}

\section{INTRODUCTION}

The metal-mediated coupling and polymerization of unsaturated organic molecules are important industrial processes, and the polymers obtained are of great practical importance. ${ }^{1-4}$ In particular, the synthesis of heterocycles resulting from coupling and cycloaddition reactions of isocyanides with other hetero-element unsaturated species is a widely-used technique. ${ }^{5}$ Groundbreaking work by Passerini ${ }^{6}$ and $\mathrm{Ugi}^{7-9}$ led to a dramatic expansion of the study of cyanide and isocyanide coupling chemistry, most notably their metal catalyzed oligomerization and polymerization reactions. ${ }^{10-12}$ However, knowledge of their mechanistic details remains limited. Some of the earliest coupling reactions were shown to be mediated by Grignard reagents ${ }^{13}$ and other main group metal halides, ${ }^{14-15}$ but most of the work on the 
mechanism of catalytic coupling of isocyanides has involved transition metal complexes either of the group 10 noble metals or various first row transition metal complexes. ${ }^{16,17}$

Yamamoto and coworkers first recognized that cobalt and nickel complexes displayed high catalytic activity towards isocyanides. ${ }^{16}$ Nolte and Drenth examined the mechanism of the coupling reactions and concluded that the Lewis-acidic character of the metal center is essential to the propagation of polymerization (Scheme 1). ${ }^{17}$ The expansion of the catalytic work to the main group elements was first realized for the electropositive metals of groups 1 and $2 .{ }^{18-20}$ Isocyanide coordination to alkali metal cations, followed by nucleophilic attack of alkyl or amido groups was reported by Walborsky and Lappert to form lithioaldimine ${ }^{18}$ and $\beta$-diketiminate ${ }^{19,20}$ complexes respectively. Subsequent coupling and migratory insertion reactions of isocyanides into metal-ligand and metal-metal bonds of main group complexes have been reported, but mechanistic information on these reactions is scarce. ${ }^{21-26}$

Scheme 1. Transition metal mediated coupling of isocyanides.

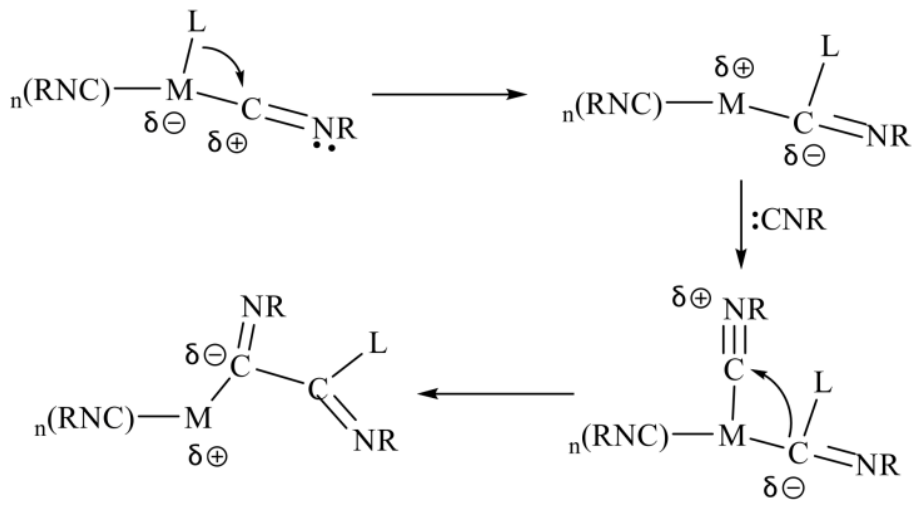

Recently, we reported the synthesis of the adduct $\left(\mathrm{Ar}^{\mathrm{Me}}\right)_{2} \mathrm{GeCNBu}^{\mathrm{t}}$, which underwent isobutene elimination under mild conditions to give the hydride/cyanide $\left(\mathrm{Ar}^{\mathrm{Me}}{ }_{2}{ }_{2} \mathrm{Ge}(\mathrm{H}) \mathrm{CN} .{ }^{27}\right.$ We now report the isolation and structural characterization of a series of compounds arising from the insertion reactions of the simplest isocyanide, MeNC, with the germylene $\mathrm{Ge}\left(\mathrm{Ar}^{\mathrm{Me}}\right)_{2}\left(\mathrm{Ar}^{\mathrm{Me}} 6=\mathrm{C}_{6} \mathrm{H}_{3}-2,6\left(\mathrm{C}_{6} \mathrm{H}_{2}-2,4,6-\mathrm{Me}_{3}\right)_{2}\right)^{28}$ and supply details of the mechanism of the subsequent transformation. We show that the simple adduct $\left(\mathrm{Ar}^{\mathrm{Me}}\right)_{2} \mathrm{GeCNMe}(\mathbf{1})$, is formed in the first instance, whereupon the coordinated methylisocyanide molecule in $\mathbf{1}$ then undergoes a spontaneous migratory insertion into one of the $\mathrm{Ge}-\mathrm{C}(\mathrm{Ar})$ bonds to form 
the structural isomer $\left(\mathrm{Ar}^{\mathrm{Me}}{ }_{6}\right) \mathrm{Ge}(\mu-\mathrm{CNMe})\left(\mathrm{Ar}^{\mathrm{Me}}{ }_{6}\right)\left(\mathbf{1}^{\prime}\right)$. If the germylene is treated with excess isocyanide, two additional molecules of methylisocyanide are incorporated into $\mathbf{1}^{\prime}$ to form $\left(\mathrm{Ar}^{\mathrm{Me}}{ }_{6}\right) \mathrm{GeC}(\mathrm{NHMe}) \mathrm{C}\left(\mathrm{NCH}_{2}\right) \mathrm{C}\left(\mathrm{Ar}^{\mathrm{Me}}{ }_{6}\right) \mathrm{NMe},\left(\mathbf{3}^{\prime \prime}\right)$ (Scheme 2) via a two-fold insertion intermediate. The isolation of intermediates $\mathbf{1}, \mathbf{1}^{\prime}$, and the final product $\mathbf{3}^{\prime \prime}$, coupled with a detailed computational study of the mechanism by density functional theory (DFT) provide new insights on the migratory insertion and oligomerization reactions of isocyanides with main group complexes.

\section{Scheme 2. Formation of 3" via migratory insertion of methylisocyanide.}

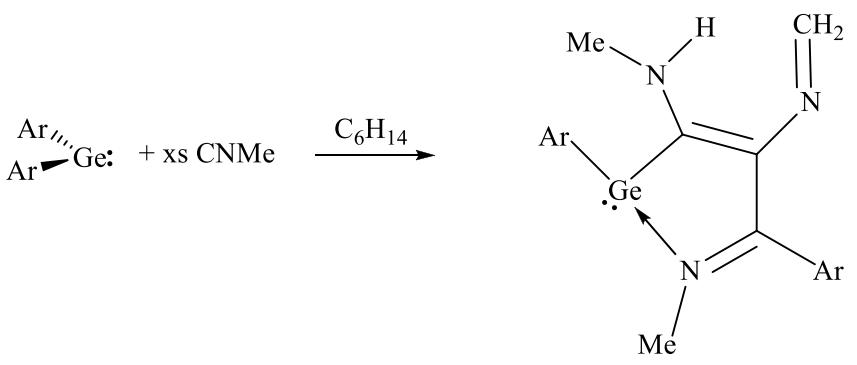

\section{EXPERIMENTAL}

General Experimental Procedures. All manipulations were carried out by using modified Schlenk techniques under an atmosphere of $\mathrm{N}_{2}$. All solvents were distilled from $\mathrm{NaK}$ and degassed prior to use. $\mathrm{Ge}\left(\mathrm{Ar}^{\mathrm{Me}}\right)_{2}$ and $\mathrm{Sn}\left(\mathrm{Ar}^{\mathrm{Me}}\right)_{2}$ were prepared according to literature procedures. ${ }^{28}$ Methylisocyanide was prepared by literature methods and stored as a $1 \underline{\mathrm{M}}$ solution in hexanes. ${ }^{29}{ }^{1} \mathrm{H}$ and ${ }^{13} \mathrm{C}$ NMR were obtained on a Varian Inova 400 and $600 \mathrm{MHz}$ spectrometers and referenced to the residual protons in the solvent. Melting points were measured in glass capillaries sealed under $\mathrm{N}_{2}$ by using a Mel-Temp II apparatus and are uncorrected. Infrared spectra were recorded using attenuated total reflectance (ATR) on a Bruker Tensor-27 infrared spectrometer. Variable temperature UV-vis data were recorded on a Cary 300 Scan spectrometer attached to a Cary Temperature Controller.

$\left(\mathbf{A r}^{\mathrm{Me}_{6}}\right)_{2}$ GeCNMe (1): Method A: Methylisocyanide (1.5 mmol) was added to a stirred slurry of $\mathrm{Ge}\left(\mathrm{Ar}^{\mathrm{Me}}\right)_{2}(0.35 \mathrm{~g}, 0.5 \mathrm{mmol})$ in hexane $(15 \mathrm{~mL})$ at room temperature. The solution was allowed to stir 
until all the solids had dissolved and the purple color of the solution had faded to a homogeneous yellow (ca. 15 min.) The reaction mixture was stored overnight at $c a .7^{\circ} \mathrm{C}$ to yield yellow crystals of $\mathbf{1}$ suitable for X-ray diffraction studies. If allowed to stand at $c a .7^{\circ} \mathrm{C}$ for more than 3 days, the color of the solution changed to deep red to yield mixtures of $\mathbf{1}$ and $\mathbf{3}^{\prime \prime}$. Method B: Methylisocyanide (2 mmol) was added to a stirred slurry of $\mathrm{Ge}\left(\mathrm{Ar}^{\mathrm{Me}}\right)_{2}(0.35 \mathrm{~g}, 0.5 \mathrm{mmol})$ in pentane $(30 \mathrm{~mL})$ at room temperature. The color of the solution became yellow immediately. All volatile materials were immediately removed to afford $\mathbf{1}$ as a yellow powder in quantitative yield. Method A yield: $60 \%(0.22 \mathrm{~g})$. Mp: $186{ }^{\circ} \mathrm{C}$ (red oil). Due to high fluxionality, ${ }^{1} \mathrm{H}$ and ${ }^{13} \mathrm{C}$ NMR spectra could not be obtained even with cooling to $-50{ }^{\circ} \mathrm{C} . \quad \lambda_{\max }(\varepsilon): 297$ nm. IR (ATR) v(C-N): $2161 \mathrm{~cm}^{-1}(\mathrm{~m})$.

$\left(\mathrm{Ar}^{\mathrm{Me}}{ }_{6}\right) \mathrm{Ge}(\boldsymbol{\mu}-\mathrm{CNMe})\left(\mathrm{Ar}^{\mathrm{Me}}{ }_{6}\right)\left(\mathbf{1}^{\prime}\right):$ To a stirred slurry of $\mathrm{Ge}\left(\mathrm{Ar}^{\mathrm{Me}}\right)_{2}(0.35 \mathrm{~g}, 0.5 \mathrm{mmol})$ in hexane $(20 \mathrm{~mL})$ methylisocyanide $(0.75 \mathrm{mmol})$ was added at room temperature. The purple color of the solution became yellow, and the reaction mixture was allowed to stir at room temperature overnight, whereupon the color of the solution changed to deep red. All of the volatiles were removed under reduced pressure, and the reddish oil was extracted with ca. $20 \mathrm{~mL}$ pentane and filtered via a filter tip cannula. Free $\mathrm{Ge}\left(\mathrm{Ar}^{\mathrm{Me}}\right)_{2}$ and complex 1 were separated from the product by overnight storage of the dilute pentane solution at $\mathrm{ca}$. -18 ${ }^{\circ} \mathrm{C}$. The mother liquor was decanted from the solids and the volume of the solution was reduced by half and stored at $c a .-18{ }^{\circ} \mathrm{C}$ overnight to yield deep red crystals of 1'. Yield: $29 \%(0.11 \mathrm{~g}) . \mathrm{Mp}: 186^{\circ} \mathrm{C}$ (red oil). ${ }^{1} \mathrm{H}$ NMR (600 MHz, $\left.\mathrm{C}_{6} \mathrm{D}_{6}, 25^{\circ} \mathrm{C}\right): \delta 1.85$ (br, 3H, p-Me), 1.89 (s, 3H, N-Me), 2.21 (s, 6H, o-Me), 2.31 (br, 6H, o-Me), 2.37 (s, 3H, p-Me), 6.58 (br, 1H, m-Mes), 6.77 (s, 1H, m-Mes), 6.82 (d, 4H, m$\left.\mathrm{C}_{6} \mathrm{H}_{3}\right), 7.02\left(\mathrm{t}, 1 \mathrm{H}, \mathrm{p}-\mathrm{C}_{6} \mathrm{H}_{3}\right), 7.11\left(\mathrm{t}, 1 \mathrm{H}, \mathrm{p}-\mathrm{C}_{6} \mathrm{H}_{3}\right) .{ }^{13} \mathrm{C}$ NMR could not be obtained. $\lambda_{\max }(\varepsilon): 377 \mathrm{~nm}$. IR (ATR) $v(\mathrm{C}-\mathrm{N}): 1710 \mathrm{~cm}^{-1}(\mathrm{~m})$.

$\left(\mathrm{Ar}^{\mathrm{Me}}{ }\right) \mathbf{G e C}(\mathbf{N H M e}) \mathbf{C}(\mathbf{N M e}) \mathbf{C}\left(\mathrm{Ar}^{\mathrm{Me}}\right) \mathbf{N M e}\left(\mathbf{3}^{\prime \prime}\right)$ : To a stirred slurry of $\mathrm{Ge}\left(\mathrm{Ar}^{\mathrm{Me}_{6}}\right)_{2}(0.35 \mathrm{~g}, 0.5 \mathrm{mmol})$ in hexane $(20 \mathrm{~mL})$ methylisocyanide $(5 \mathrm{mmol})$ was added at room temperature. The purple color of the solution became yellow, and the reaction mixture was allowed to stir at room temperature for two days, whereupon the color of the solution changed to deep red. All of the volatile components were removed 
under reduced pressure, and the reddish oil was extracted with $c a .20 \mathrm{~mL}$ pentane and filtered via a filter tip cannula. Free $\mathrm{Ge}\left(\mathrm{Ar}^{\mathrm{Me}} 6\right)_{2}$ was separated from the product by overnight storage of the dilute pentane solution at $c a .-18^{\circ} \mathrm{C}$. The mother liquor was decanted from the solids and the volume of the solution was reduced by half. Storage at $c a .-18^{\circ} \mathrm{C}$ overnight yielded deep red crystals of 3'? Yield: $23 \%(0.09$ g). Mp: $158^{\circ} \mathrm{C}(\mathrm{dec}) .{ }^{1} \mathrm{H}$ NMR $\left(400 \mathrm{MHz}, \mathrm{C}_{6} \mathrm{D}_{6}, 25^{\circ} \mathrm{C}\right): \delta 1.98\left(\mathrm{~s}, 3 \mathrm{H}, \mathrm{CNMe}\right.$ or $\left.\mathrm{Ar}^{M e} 6\right), 2.07(\mathrm{~s}, 3 \mathrm{H}$, $\mathrm{CNMe}$ or $\left.\mathrm{Ar}^{M e} 6\right), 2.08$ (s, 6H, o-Me), 2.10, 2.11, 2.13, 2.21, 2.26, 2.34 (all s, 3H, CNMe or $\mathrm{Ar}^{M e} 6$ ), 4.56 (q, 1H, N-H), 6.24 (d, 1H, m- $\mathrm{C}_{6} \mathrm{H}_{3}$ ), 6.59 (br, 2H, m-Mes) 6.76 (br, 2H, m-Mes), 6.79 (br, 2H m-Mes), 6.88 $\left(\mathrm{d}, 2 \mathrm{H}, \mathrm{m}-\mathrm{C}_{6} \mathrm{H}_{3}\right) 6.96\left(\mathrm{dd}, 1 \mathrm{H}, \mathrm{p}-\mathrm{C}_{6} \mathrm{H}_{3}\right), 6.98\left(\mathrm{~d}, 2 \mathrm{H}, \mathrm{m}-\mathrm{C}_{6} \mathrm{H}_{3}\right), 7.02\left(\mathrm{dd}, 1 \mathrm{H}, \mathrm{p}-\mathrm{C}_{6} \mathrm{H}_{3}\right), 7.16(\mathrm{~m}, 2 \mathrm{H}$, $\left.\mathrm{NCH}_{2}\right) .{ }^{13} \mathrm{C}$ NMR spectrum could not be obtained. $\lambda_{\max }(\varepsilon): 343 \mathrm{~nm}, 421 \mathrm{~nm}$. IR (ATR) $v(\mathrm{C}=\mathrm{C}) 639 \mathrm{~cm}^{-}$ ${ }^{1}$ (br), $v(\mathrm{C}=\mathrm{N}) 1729 \mathrm{~cm}^{-1}$ (br).

$\left(\mathbf{A r}^{\mathrm{Me}}\right)_{2}{ }_{2} \mathrm{SnCNMe}$ : Methylisocyanide $(5 \mathrm{mmol})$ was added via a syringe to a stirred solution of $\operatorname{Sn}\left(\mathrm{Ar}^{\mathrm{Me}}\right)_{2}(0.37 \mathrm{~g}, 0.5 \mathrm{mmol})$ in $c a .20 \mathrm{~mL}$ of a $1: 1$ pentane toluene mixture. The reaction mixture was allowed to stand at $c a .-78^{\circ} \mathrm{C}$ for two weeks, after which time a yellow power precipitated from the purple solution. The solid was maintained at $c a .-78^{\circ} \mathrm{C}$ via cooling in a dry ice/acetone bath while the mother liquor was decanted off, and an FTIR spectrum could quickly be obtained before complete dissociation of MeNC and conversion of the yellow powder to a purple solid which was confirmed to be $\mathrm{Sn}\left(\mathrm{Ar}^{\mathrm{Me}} 6\right)_{2}$ by ${ }^{1} \mathrm{H}$ NMR spectroscopy. dec: $c a .-50{ }^{\circ} \mathrm{C}$ (free CNMe and $\left.\mathrm{Sn}\left(\mathrm{Ar}^{\mathrm{Me}_{6}}\right)_{2}\right)$. IR (ATR): v(C-N) $2197 \mathrm{~cm}^{-1}$.

X-ray crystallographic data collection. Crystals of $\mathbf{1}, \mathbf{1}^{\prime}$, and $\mathbf{3}^{\prime \prime}$ suitable for single crystal X-ray diffractometry were removed from a Schlenk flask under a stream of $\mathrm{N}_{2}$ and immediately covered with a layer of hydrocarbon oil. A single crystal was selected, attached to a glass fiber on a copper pin, and placed in the cold $\mathrm{N}_{2}$ stream of the diffractometer. All crystallographic calculations were performed on a personal computer (PC) with a Pentium 3.20 GHz processor and 4 GB of extended memory. Data were collected based upon a single component, processed with SAINT, ${ }^{30}$ and corrected for Lorentz and polarization effects and absorption using Blessing's method as incorporated into the program SADABS. ${ }^{31}$ 
The structures were determined by direct methods using the program XS. ${ }^{33}$ Refinement of the structure was achieved using the program XL. ${ }^{34}$ All of the non-hydrogen atoms were located initially or from one difference-Fourier map least-squares cycle and convergence proceeded quickly with all of the hydrogen atoms located from a subsequent difference-Fourier map. See SI for more details.

Computational details. All calculations were done with Turbomole v6.3 program. ${ }^{33}$ The geometries of studied systems were optimized with DFT using the hybrid PBE1PBE exchange-correlation functional ${ }^{34}$ in combination with the TZVP basis sets. ${ }^{35}$ Due to the size of terphenyl ligands in experimental compounds, calculations were performed for model systems with smaller phenyl substituents. All reported energy values represent reaction enthalpies at $0 \mathrm{~K}$.

In addition to the mechanism discussed in the main text, a number of other plausible pathways were investigated with calculations. For example, addition of the second equivalent of isocyanide to the germanium prior to phenyl migration resulted in Ge-C bond breaking and simple shuffling of the coordinated isocyanides. If, on the other hand, the second equivalent of methylisocyanide was reacted directly with the carbon in the coordinated isocyanide, coupling of the two isocyanides to a free diamine was observed. Similarly, an attack of the third equivalent of a methylisocyanide to a carbon atom in the azagermacyclobutene intermediate led to a $\mathrm{C}-\mathrm{C}$ bond formation and to a structure with a three-membered CNN-ring with no apparent further reactivity. The possibility of hydrogen transfer occurring before the formation of $\mathbf{3}^{\prime} \mathbf{P h}$ was also tested computationally, but it resulted only in a formation of a five-membered ring with no apparent further reactivity. Hence, the mechanism discussed in the main text was the only plausible reaction pathway connecting 1 to $\mathbf{3}^{\prime \prime} \mathbf{P h}$ that could be identified computationally.

\section{RESULTS AND DISCUSSION}

Treatment of a purple solution of $\mathrm{Ge}\left(\mathrm{Ar}^{\mathrm{Me}}\right)_{2}$ with an excess of MeNC immediately yielded a

bright yellow solution, indicative of the formation of the adduct species, 1. Storage of this solution at $c a$. $-18^{\circ} \mathrm{C}$ yielded $\mathrm{X}$-ray quality yellow crystals of the germylene - isocyanide adduct (See Figure 1 for 
structural details). The bond dissociation energy for $\mathbf{1}$ was found to be $-20 \mathrm{~kJ} \mathrm{~mol}^{-1}$ by Van't Hoff analysis of the variable temperature UV-vis spectrum, and it exists in equilibrium with free MeNC and $\mathrm{Ge}\left(\mathrm{Ar}^{\mathrm{Me}}\right)_{2}$. If the reaction is continued overnight, the yellow solution changes to deep red, and the threefold insertion product, $\mathbf{3}^{\prime \prime}$, can be isolated in moderate yield (ca. $\left.25 \%\right)$.
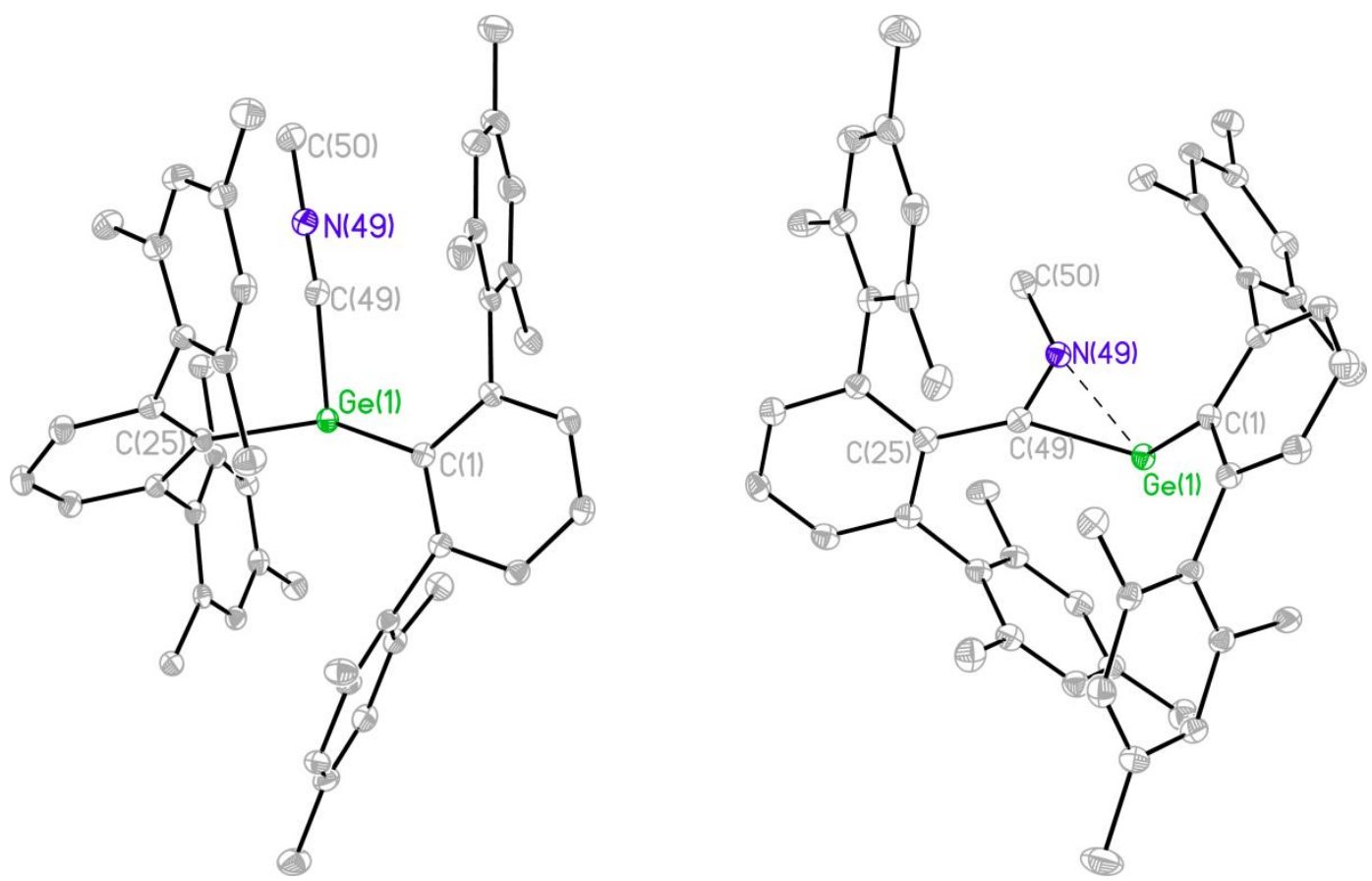

Figure 1. Thermal ellipsoid (30\%) drawing of $\mathbf{1}$ (left) and 1' (right). Carbon-bound hydrogen atoms and a cocrystallized hexane molecule (in $\mathbf{1}^{\prime}$ ) are not shown for clarity. Selected bond lengths ( $(\AA)$ and angles (deg) 1: Ge(1) - C(1) 2.057(3), Ge(1) - C(25) 2.060(3), Ge(1) - C(49) 2.028(4), C(49) - N(49) 1.164(5), $\mathrm{N}(49)-\mathrm{C}(50)$ 1.422(5), C(1) - Ge(1) - C(25) 116.6(1), C(Ar) - Ge(1) - C(49) (ave) 96.4(1), Ge(1) $\mathrm{C}(49)-\mathrm{N}(49)$ 156.6(3). 1': $\mathrm{Ge}(1)-\mathrm{C}(1)-2.046(4), \mathrm{Ge}(1)-\mathrm{C}(49) 2.021(5), \mathrm{Ge}(1)-\mathrm{N}(49)$ 2.104(4), $\mathrm{C}(49)-\mathrm{C}(25) 1.496(4), \mathrm{C}(49)-\mathrm{N}(49) 1.271(5), \mathrm{N}(49)-\mathrm{C}(50) 1.465(6), \mathrm{C}(1)-\mathrm{Ge}(1)-\mathrm{C}(49) 107.4(2)$, $\mathrm{Ge}(1)-\mathrm{C}(49)-\mathrm{N}(49) 75.6(3), \mathrm{C}(49)-\mathrm{N}(49)-\mathrm{C}(50)$ 128.2(4), Ge(1) - N(49) - C(50) 155.2(3), C(25) $\mathrm{C}(49)-\mathrm{Ge}(1) 150.4(3)$.

Adduct formation is often an initial step in the reaction of main group species with unsaturated molecules, and synergistic interactions between main group species and the frontier orbitals of the ligand 
propagate further reaction. ${ }^{36}$ The infra-red spectrum of $\mathbf{1}$ shows a slight shift of the $\mathrm{C}-\mathrm{N}$ stretching band to higher frequency $\left(2165 \mathrm{~cm}^{-1}\right)$ in comparison to the free isocyanide $\left(c f .2161 \mathrm{~cm}^{-1}\right)$, indicative of $\mathrm{n} \rightarrow \pi^{*}$ back-bonding between the germanium(II) lone pair and the $\pi^{*}$ orbital of the isocyanide ligand. These data are in good agreement with the spectrum of $\left(\mathrm{Ar}^{\mathrm{Me}}{ }_{6}\right)_{2} \mathrm{GeCNBu}^{\mathrm{t}}$, in which the $\mathrm{C}-\mathrm{N}$ stretching band is 5 $\mathrm{cm}^{-1}$ lower in frequency. ${ }^{27}$ In contrast, the tin congener of $\mathbf{1},\left(\mathrm{Ar}^{\mathrm{Me}}{ }_{6}\right)_{2} \mathrm{SnCNMe}$, can only be isolated at low temperatures with use of a ten-fold excess of MeNC, and readily dissociates to $\mathrm{Sn}\left(\mathrm{Ar}^{\mathrm{Me}}\right)_{2}$ and $\mathrm{MeNC}$ above $c a .-50{ }^{\circ} \mathrm{C}$. Although the bonding between MeNC and $\mathrm{Sn}\left(\mathrm{Ar}^{\mathrm{Me}} 6\right)_{2}$ is weak, the $\mathrm{C}-\mathrm{N}$ stretching band in the infra-red spectrum of $\left(\mathrm{Ar}^{\mathrm{Me}}\right)_{2} \mathrm{SnCNMe}_{\mathrm{N}}$ is shifted by $36 \mathrm{~cm}^{-1}$ to higher frequency. The direct comparison between isoleptic tetrylene - isocyanide adducts challenges the traditional dogma that the hypsochromic shift of the $\mathrm{C}-\mathrm{N}$ stretching band is directly proportional to the $\mathrm{M}-\mathrm{C}$ bond strength, and that the back-bonding interaction in complex 1 plays a large role in the strength of the dative bond. ${ }^{37}$

To suppress the subsequent isocyanide insertions which lead to the formation of $\mathbf{3}^{\prime \prime}$, only 1.5 equivalents of MeNC were added to a solution of the germylene to produce the one-fold insertion product, $\mathbf{1}^{\prime}$. X-ray quality red crystals of $\mathbf{1}^{\prime}$ (structure, Figure 1) had a Ge(1) - C(1) bond length of 2.046(4) $\AA$, which is very close to that in $\mathrm{Ge}\left(\mathrm{Ar}^{\mathrm{Me}} 6\right)_{2}(c f .2 .033(4) \AA)$. The $\mathrm{Ge}(1)-\mathrm{C}(49)$ bond length of 2.022(5) $\AA$ is also very similar to that of the $\mathrm{Ge}-\mathrm{C}(1)$ bond. The $\mathrm{C}(1)-\mathrm{Ge}(1)-\mathrm{C}(49)$ bond angle of $107.4(2)^{\circ}$ is less than that $\left(114.4(2)^{\circ}\right)$ in $\mathrm{Ge}\left(\mathrm{Ar}^{\mathrm{Me}} 6\right)_{2} \cdot{ }^{28}$ The $\mathrm{C}(49)-\mathrm{N}(49)$ bond length of $1.271(5) \AA$ in the isocyanide indicates the conversion of the triple bond to a double bond, and the lowering of the bond order is confirmed by a decrease in the C-N stretching frequency to $1710 \mathrm{~cm}^{-1}$ in comparison to the 2165 $\mathrm{cm}^{-1}$ in $\mathbf{1}$. Additionally, the nitrogen lone pair is now datively bound to the germanium through the $\mathrm{p}$ orbital of the germylene. The Ge(1) - N(49) distance (2.104(4) $\AA$ ) is long, and the dative bond creates an acute angle $75.6(3)^{\circ}$ at $\mathrm{C}(49)$. These two factors, coupled with a broadened ${ }^{1} \mathrm{H}$ NMR spectrum for $\mathbf{1}^{\prime}$ are indicative of a relatively weak Ge-N bond that is dissociating in solution. 
Scheme 3. Calculated reaction pathway for the formation of $3^{\prime \prime}$ Ph.

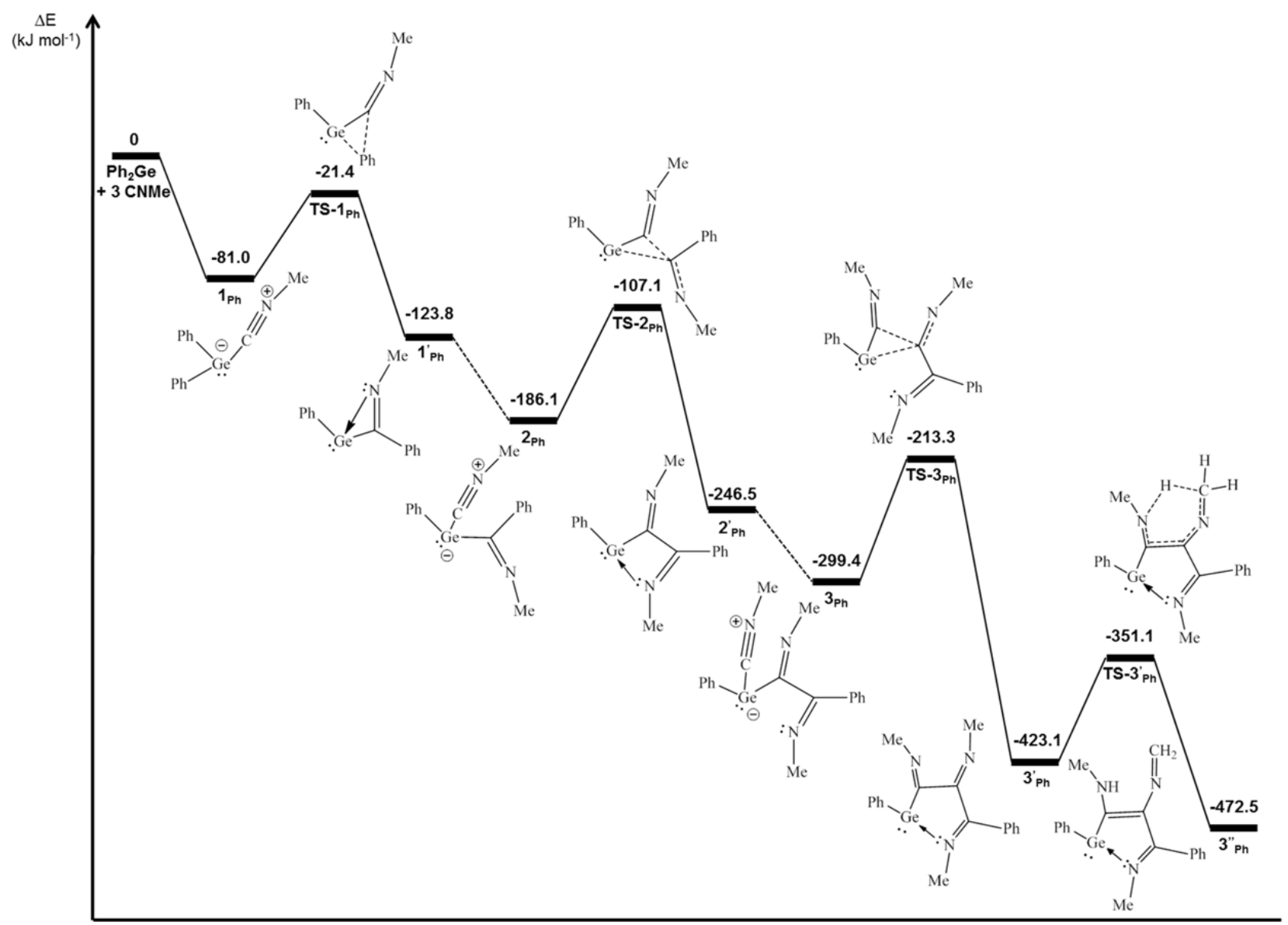

In order to understand the initial migratory insertion of MeNC: into the $\mathrm{Ge}(1)-\mathrm{C}(\mathrm{Ar})$ bond, we examined the possible reaction pathway (Scheme 3) for the formation of $\mathbf{3}^{\prime \prime}$ by use of density functional theory (DFT) and via the isolation of the intermediates $\mathbf{1}$ and $\mathbf{1}^{\prime}$ and the product $\mathbf{3}^{\prime \prime}$. The model complex, $\mathrm{Ge}\left(\mathrm{C}_{6} \mathrm{H}_{5}\right)_{2}$ was used to study the reaction pathway computationally. The formation of the model adduct species $\mathbf{1}_{\mathbf{P h}}$ was found to be more stable than the free starting materials. A transition state $\left(\mathrm{TS}-1_{\mathrm{Ph}}\right)$ was found for the formation of $\mathbf{1}^{\prime} \mathbf{P h}$ which involves the concerted migration of the isocyanide molecule into the $\mathrm{Ge}-\mathrm{C}(\mathrm{Ph})$ bond. We hypothesize that the insertion reaction depends on having a highly activated, electron rich germanium atom, and removal of this electron density is accomplished either by dissociating to the free starting materials, or migratory insertion of the isocyanide molecule. The activation energy for 
this process is predicted to be less than the energy gained from the dative bond formation, and the coordination number at the germanium is maintained though a weak dative interaction with the $\beta$-nitrogen of the imino moiety. As mentioned earlier, the $\mathrm{N}-\mathrm{Ge}$ dative bond in $\mathbf{1}^{\prime}$ is relatively weak, and in the presence of excess isocyanide, it is readily broken and replaced by a second isocyanide molecule which possesses a greater electron donating capability than the imino-nitrogen. The second adduct species, $\mathbf{2}_{\mathbf{P h}}$, undergoes a further migratory insertion process (TS-2 $\mathbf{P h})$ in a manner similar to the first insertion, yielding an azagermacyclobutene complex $\mathbf{2}^{\prime}$ Ph which, like $\mathbf{1}_{\mathbf{P h}}{ }_{\mathbf{P h}}$, possesses a dative interaction between the $\gamma$-nitrogen and germanium. As before, formation of an isocyanide adduct complex of $\mathbf{2}^{\prime} \mathbf{P h}$ is energetically favored, and is rapidly followed by a third migration of MeNC to yield the heterocyclic complex $\mathbf{3}^{\prime}$ Ph. The C-H bond activated complex, $\mathbf{3}^{\prime \prime}{ }_{\mathbf{P h}}$, is predicted to be more stable than $\mathbf{3}_{\mathbf{P h}}$ by $49 \mathrm{~kJ}$ mol $^{-1}$ and it adopts a cyclopentadienyl-type structure after hydrogen transfer. The final product $\mathbf{3}^{\prime \prime}{ }_{\mathbf{P h}}$ is predicted to be favored over the tris-imino complex $\mathbf{3}_{\mathbf{P h}}^{\prime}$ for steric reasons. We hypothesize that there is considerable steric strain placed on the $\alpha$ and $\beta$ imine bonds by the aryl ligands, and the bond reduction allows these bonds to bend inward away from the bulky aryl ligands. Relief of this bond strain, coupled with the energy gained by allowing the $\mathrm{C}-\mathrm{N}$ bond to freely rotate away from the germanium-bound ligands, is sufficient to overcome the calculated activation energy of $72 \mathrm{~kJ} \mathrm{~mol}^{-1}$. 


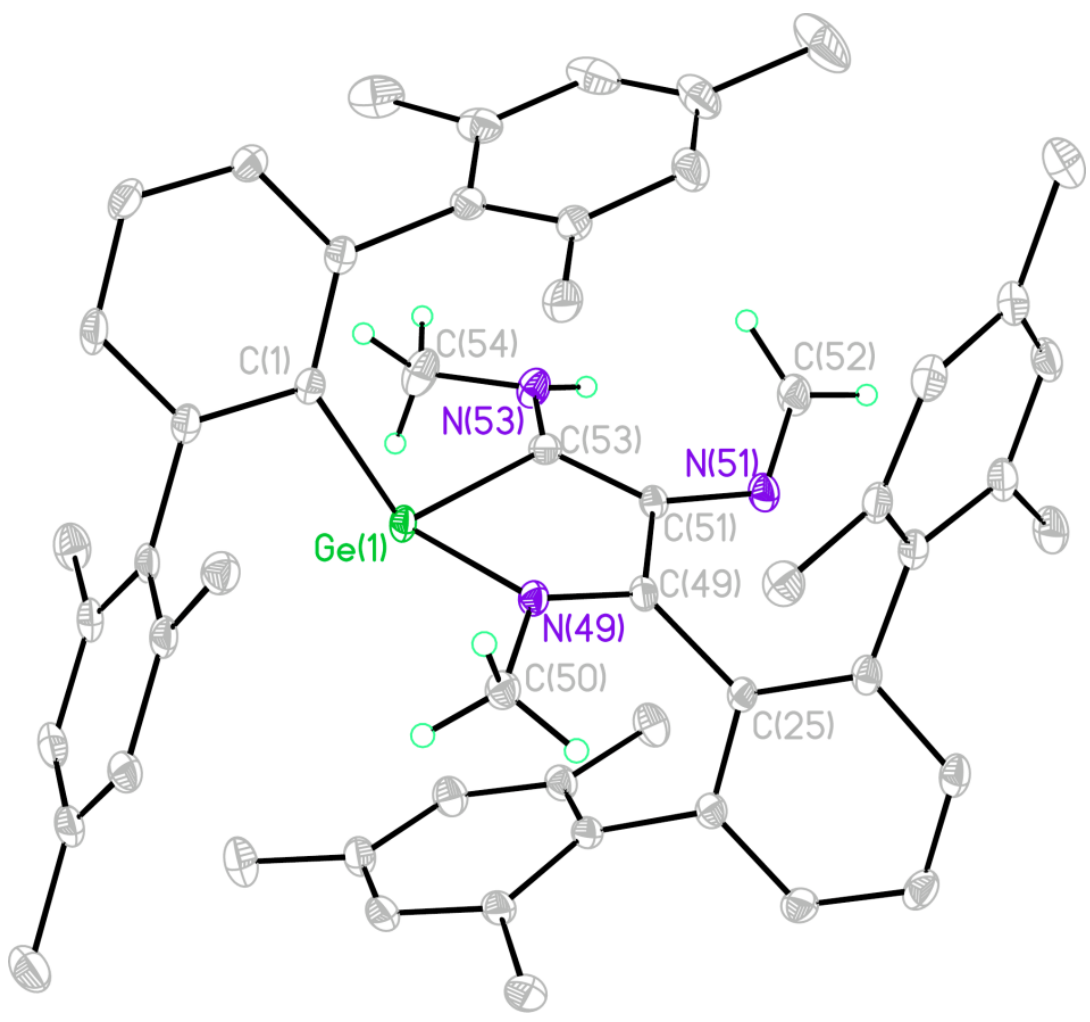

Figure 2. Thermal ellipsoid (30\%) drawing of 3". Carbon-bound hydrogen atoms of the m-terphenyl ligands are not shown for clarity. Selected bond lengths $(\AA)$ and angles (deg): Ge(1) - C(1) 2.036(3), $\mathrm{Ge}(1)-\mathrm{C}(53)$ 1.992(3), Ge(1) - N(49) 1.968(2), C(49) - N(49) 1.333(3), N(49) - C(50) 1.455(3), C(25)

- C(49) 1.510(3), C(49) - C(51) 1.423(4), C(51) - N(51) 1.413(3), N(51) - C(52) 1.265(4), C(51) - C(53) 1.401(4), $\mathrm{C}(53)-\mathrm{N}(53) 1.345(4), \mathrm{N}(53)-\mathrm{C}(54) 1.460(4), \mathrm{C}(1)-\mathrm{Ge}(1)-\mathrm{C}(53) 107.9(1), \mathrm{C}(1)-\mathrm{Ge}(1)-$ $\mathrm{N}(49)$ 108.5(1), Ge(1) - N(49) - C(49) 111.4(2), Ge(1) - C(53) - C(51)110.2(2), C(51) - N(51) - C(52) 120.1(3), C(49) - N(49) - C(50) 123.8(2).

Deep red crystals of $\mathbf{3}^{\prime \prime}$ suitable for X-ray diffraction were isolated from a concentrated pentane solution, and the structure is shown in Figure 2. The diene fragment comprised of $N(49)-C(49)-C(51)$ $-\mathrm{C}(53)$ is twisted $13.7(4)^{\circ}$ from planarity, and the sum of angles within the five membered ring is 560.5 o. The $\mathrm{C}(51)-\mathrm{N}(51)$ and $\mathrm{C}(53)-\mathrm{N}(53)$ bond lengths are 1.413(3) and 1.345(5) $\AA$, and the contracted distance of the $\mathrm{sp}^{2}-\mathrm{sp}^{3} \mathrm{C}(53)-\mathrm{N}(53)$ bond is indicative of conjugation between the nitrogen lone pair and the unsaturated heterocycle. The conjugation is further supported by broadening of the ${ }^{1} \mathrm{H}$ NMR 
spectrum for the amido and alkenyl protons. The $\mathrm{C}(49)-\mathrm{N}(49)$ bond (1.333(3) $\AA$ ) maintains its imido character, and the $\mathrm{Ge}(1)-\mathrm{N}(49)(1.968(2))$ is short for germanium bound dative bonds. We attribute the increased strength of the germanium-nitrogen dative bond to a decrease in steric bulk at the germanium atom as well as ability for the $\gamma$ isocyanide fragment to freely coordinate without causing undue bond strain as in $\mathbf{1}^{\prime}$. Migratory insertion reactions have been reported by our group for the reaction of $\mathrm{CO}$ with germylenes, although no $\mathrm{CO}$ adduct analogues of $\mathbf{1}^{\prime}$ could be isolated.$^{38}$ Driess and coworkers have also reported coupling reactions for isocyanides with silylenes stabilized by $\beta$-diketiminate ligands, but at present, no mechanistic information is available for these reactions. ${ }^{39}$

\section{CONCLUSION}

In conclusion, we have prepared an azagermacyclopentadienyl complex by the threefold insertion of methylisocyanide into the germanium-carbon bond of a diarylgermylene. Additionally, we have isolated key intermediates in this reaction which, along with DFT calculations, have provided further insight for the coupling reactions of unsaturated organic molecules with heavy carbene analogues. Further study of coupling reactions between $\mathbf{1}$ and other substrates are underway, as well as investigations into catalytic capabilities of the migratory insertion reactions.

\section{ASSOCIATED CONTENT}

\section{Supporting Information}

Crystallographic information files for $\mathbf{1}, \mathbf{1}^{\prime}$, and $\mathbf{3}^{\prime \prime} ;{ }^{1} \mathrm{H}$ NMR spectra for $\mathbf{1}^{\prime}$ and $\mathbf{3}^{\prime}$; temperature-dependent UV-vis spectra for $\mathbf{1}$; tables of crystallographic data and collection parameters for $\mathbf{1}, \mathbf{1}^{\prime}$, and $\mathbf{3}^{\prime \prime}$.

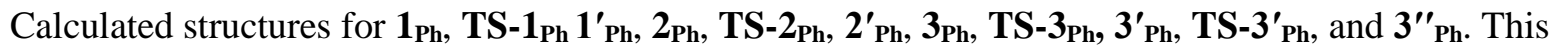
information is available free of charge via the Internet at http://pubs.acs.org. 


\section{ACKNOWLEDGEMENTS}

We thank the US Department of Energy (DE-FG02-07ER46475), the Academy of Finland and the Technology Industries of Finland Centennial Foundation for funding.

\section{AUTHOR INFORMATION}

\section{Corresponding Author}

pppower@ucdavis.edu

\section{REFERENCES}

1. Suginome, M.; Ito, Y. Adv. Polym. Sci. 2004, 171, 77-136.

2. Marcilly, C. Journal of Catalysis. 2003, 47-62.

3. Malpass, D. Introduction to Industrial Polyethylene. Wiley-Scrivener. 2010.

4. Millich, F. Macromol. Rev. 1980, 15, 207-253.

5. Frühauf, H.-W. Chem. Rev. 1997, 97, 523-596.

6. Passerini, M.; Ragni, G.; Gazz. Chim. Ital. 1931, 61, 964-969.

7. Dömling, A.; Ugi, I. Angew. Chem. Int. Ed. 2000, 112, 3300-3344.

8. Ugi, I. Angew. Chem. Int. Ed. 1962, 74, 9-22.

9. Ugi, I.; Steinbrückner, C. Chem. Ber. 1961, 94, 734-742.

10. Denmark, S. E.; Fan, Y. J. Org. Chem. 2005, 70, 9667-9676.

11. Biggs-Houck, J.E.; Younai, A.; Shaw, J. T. Curr. Opin. Chem. Biol. 2010, 14, 371-386.

12. Lygin, A. V.; de Meijere, A. Angew. Chem. Int. Ed. 2010, 49, 9094-9124.

13. Ugi, I.; Fetzer, U. Chem. Ber. 1961, 94, 2239-2243.

14. Yamamoto, Y.; Hagihara, N. Nippon Kagaku Zasshi, 1968, 89, 898-900.

15. Stackman, R. W. J. Macromol. Sci. Chem. 1968, A2, 225-236.

16. Yamamoto, Y.; Takizawa, T.; Hagihara, N. Nippon Kagaku Zasshi, 1966, 87, 1355-1359. 
17. Kamer, P. C. J.; Nolte, R. J. M.; Drenth, W.; Nijs, H. L. L. M.; Kanters, J. A. J. Mol. Cat. 1988, 49, $21-32$

18. Walborsky, H. M.; Morrison, W. H.; Niznik, G. E. J. Am. Chem. Soc. 1970, 92, 6675-6676.

19. Hitchcock, P. B.; Lappert, M. F.; Layh, M. Angew. Chem. Int. Ed. 1999, 38, 501-504.

20. Hitchcock, P. B.; Lappert, M. F.; Layh, M. Chem. Commun. 1998, 201-202.

21. Li, X.; Ni, C.; Song, H.; Cui, C. Chem. Commun. 2006, 1763-1765.

22. Cook, K. S.; Piers, W. E.; Hayes, P. G.; Parvez, M. Organometallics, 2002, 21, 2422-2425.

23. MacMillan, S. N.; Tanski, J. M.; Waterman, R. Chem. Commun. 2007, 4172-4174.

24. Porchia, M.; Ossola, F.; Rossetto, G.; Zanella, P.; Brianese, N. J. Chem. Soc. Chem. Commun. 1987, $550-551$.

25. Uhl, W.; Schütz, U.; Hiller, W.; Heckel, M. Chem. Ber. 1994, 127, 1587-1592.

26. Uhl, W.; Hahn, I.; Schütz, U.; Pohl, S.; Saak, W.; Martens, J.; Manikowski, J. Chem. Ber. 1996, 129, 897-901.

27. Brown, Z. D.; Vasko, P.; Fettinger, J. C.; Tuononen, H. M.; Power, P. P. J. Am. Chem. Soc. 2012, $134,4045-4048$.

28. Simons, R. S.; Pu, L.; Olmstead, M. M.; Power, P. P. Organometallics. 1997, 16, 1920-1925.

29. Schuster, R. E.; Scott, J. E.; Casanova, J. Organic Syntheses 1973, 772-774.

30. An Empirical Correction for Absorption Anisotropy, Blessing, R. H., Acta Cryst. 1995, A51, 33-38.

31. Sheldrick, G.M., SADABS Version 2008/3, ‘Siemens Area Detector Absorption Correction’ Universität Göttingen: Göttingen, Germany.

32. Sheldrick, G. M. SHELXS97 and SHELXL97. Universität Göttingen: Göttingen, Germany, 1997.

33. TURBOMOLE v6.3 2011, a development of University of Karlsruhe and Forschungszentrum

Karlsruhe GmbH, 1989-2007, TURBOMOLE GmbH, since 2007; available from

http://www.turbomole.com. 
34. a) Perdew, J.P.; Burke, K.; Ernzerhof, M. Phys. Rev. Lett., 1996, 77, 3865-3868. b) Perdew, J.P.; Burke, K.; Ernzerhof, M. Phys. Rev. Lett., 1997, 78, 1396. c) Perdew, J.P.; Ernzerhof, M.; Burke, K. J. Chem. Phys., 1996, 105, 9982-9985. d) Adamo, C.; Barone, V. J. Chem. Phys., 1999, 110, 6158-6170.

35. Schäfer, A.; Huber, C.; Ahlrichs, R. J. Chem. Phys., 1994, 100, 5829-5835.

36. Li. J.; Hermann, M.; Frenking, G.; Jones, C. Angew. Chem. Int. Ed. 2012, 51, 8611-8614.

37. Nakamoto, K. Infrared and Raman Spectra of Inorganic and Coordination Compounds. 4th ed.; Wiley: New York, 1986.

38. Wang, X. P.; Zhu, Z. L. Peng, Y.; Lei, H.; Fettinger, J. C.; Power, P. P. J. Am. Chem. Soc. 2009, 131, 6912-6913.

39. Xiong, Y.; Yao, S.; Driess, M. Chem. Eur. J. 2009, 15, 8542-8547. 